\title{
Association between chronic obstructive pulmonary disease and gastroesophageal reflux disease: a national cross-sectional cohort study
}

Jinhee Kim", Jin Hwa Lee ${ }^{2 *}$, Yuri Kim³ ${ }^{3}$ Kyungjoo Kim³ ${ }^{3}$, Yeon-Mok Oh${ }^{4}$, Kwang Ha Yoo ${ }^{5}$, Chin Kook Rhee ${ }^{6}$, Hyoung Kyu Yoon ${ }^{7}$, Young Sam Kim ${ }^{8}$, Yong Bum Park', Sei Won Lee ${ }^{4}$ and Sang Do Lee ${ }^{4}$

\begin{abstract}
Background: Gastroesophageal reflux disease (GERD) is one of the most common causes of chronic cough and a potential risk factor for exacerbation of chronic obstructive pulmonary disease (COPD). The aim of this study was to investigate the prevalence and risk factors of GERD in patients with COPD and association between GERD and COPD exacerbation.

Methods: Data were collected from the National Health Insurance Database of Korea. The subjects were 40 years old and older, who had COPD as primary or secondary diagnosis codes and utilized health care resource to receive prescriptions of COPD medication at least twice in 2009. Univariate logistic regression was performed to understand the relationship between COPD and GERD, and multiple logistic regression analysis was performed with adjustment for several confounding factors.
\end{abstract}

Results: The prevalence of GERD in COPD patients was 28\% $(39,987 / 141,057)$. Old age, female gender, medical aid insurance type, hospitalization, and emergency room (ER) visit were associated with GERD. Most of COPD medications except inhaled muscarinic antagonists were associated with GERD. The logistic regression analysis showed that the presence of GERD was associated with increased risk of hospitalization (OR 1.54, Cl 1.50 to 1.58, $\mathrm{p}<0.001)$ and frequent ER visits (OR 1.55, Cl 1.48 to $1.62, \mathrm{p}<0.001)$.

Conclusions: The prevalence of GERD in patients with COPD was high. Old age, female gender, medical aid insurance type, and many COPD medications except inhaled muscarinic antagonists were associated with GERD. The presence of GERD was associated with COPD exacerbation.

Keywords: Gastroesophageal reflux, Obstructive lung disease, Prevalence, Exacerbation, Anticholinergic

\section{Background}

Exacerbations of chronic obstructive pulmonary disease (COPD) have a significant impact on patient quality of life and can accelerate lung function decline [1], which is associated with increased morbidity and mortality [2,3]. Gastroesophageal reflux disease (GERD) is one of the most common causes of chronic cough [4] and a potential risk factor for exacerbation of COPD [5-7]. GERD is a relatively common condition, affecting $10-29 \%$ of the western population [8] and $3-12 \%$ of Korean adults [9].

\footnotetext{
* Correspondence: jinhwalee@ewha.ac.kr

${ }^{2}$ Department of Internal Medicine, School of Medicine, Ewha Womans University, Seoul, Korea

Full list of author information is available at the end of the article
}

GER can heighten bronchial reactivity and microaspiration [10-13]. Abnormal GER was objectively assessed and clearly associated to lung diseases $[14,15]$. Laryngopharyngeal sensitivity is important in preventing pulmonary aspiration. Patients with cough and GERD have significantly reduced laryngopharyngeal sensitivity to air stimuli compared with healthy subjects [16]. COPD patients have flat diaphragm and increased intra-abdominal and negative intra-thoracic pressure, which could aggravate GER [17]. In addition, medications such as theophylline and inhaled beta-2 agonists may decrease the lower esophageal sphincter pressure, could facilitate

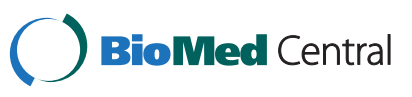

(c) 2013 Kim et al.; licensee BioMed Central Ltd. This is an Open Access article distributed under the terms of the Creative Commons Attribution License (http://creativecommons.org/licenses/by/2.0), which permits unrestricted use, distribution, and reproduction in any medium, provided the original work is properly cited. 
GER [18,19]. Therefore several small studies showed that GERD is more common in patients with COPD than that in those without COPD [20-22]. Also it has been suggested that an increase in the frequency of COPD exacerbation can be associated with the presence of GERD $[6,7,23,24]$.

We used the National Health Insurance Database of Korea and tried to answer three questions. First question was the prevalence of GERD in patients with COPD. Second one was which factors are associated with GERD in COPD patients. Third was whether the presence of GERD is associated with exacerbation of COPD even after adjusting confounding factors.

\section{Methods}

\section{Data source and ethical considerations}

The present study used the National Health Insurance claims data for medical services provided to Koreans aged $\geq 40$ years between January 1, 2009 and December 31,2009 . These data were provided by the Korean Health Insurance Review and Assessment Service (HIRA), which was established to review claims data and assess healthcare in Korea and is under the responsibility of a single agency independent from insurers, providers, and other interested parties. All Koreans are covered under the national health insurance system, and the HIRA database contains all information regarding submitted claims and prescriptions.

The HIRA claims database comprises general item, medical treatment, diagnosis, and prescription databases. The general item database contains information such as patient identifier, age, sex, and insurance type; hospital name, type, location, and medical department; and medical cost, number of days hospitalized and/or receiving outpatient, intensive care unit (ICU), and/or emergency room (ER) care. The medical treatment database contains information such as patient identifier, detailed medical treatment records, and drug administration (brand name, total days of medication, single dose, daily dose, and unit cost). The diagnosis database contains information such as patient identifier, main diagnosis, and submain diagnoses, recorded according to the International Classification of Diseases, 10th Revision (ICD-10). The prescription database contains information such as patient identifier and outpatient prescriptions. All databases were linked using a mutual identifier.

The National Evidence-Based Healthcare Collaborating Agency (NECA) ethics committee approved the present study (PIRB11-022).

\section{Study population}

The subjects of the current study were patients aged $\geq 40$ years with COPD recorded as ICD-10 codes
J42.X-J44.x (except J430) for the principal or additional diagnoses who were given prescriptions including at least one of the following medications (including oral, injected, or inhaled), at least twice per year: combinations in a single inhaler of inhaled corticosteroids (ICSs) and long-acting beta- 2 agonists (LABAs), longacting muscarinic antagonists (LAMAs), LABAs, short-acting muscarinic antagonists (SAMAs), inhalers with both short-acting beta- 2 agonists (SABAs) and SAMAs, oral beta-2 agonists, or theophylline.

Patients with more than one claim per year due to cancer (C00.x-C97.x) and/or cerebrovascular disease (I60.x-I69.x) were excluded from this study because the enormous expenses claimed for treatment of these diseases were difficult to distinguish from COPD- and GERD-related medical services. Additionally, through consultation with six physicians of pulmonary medicine, we decided to exclude patients with more than one claim per year for hiatal hernia (K449), gastric surgery (K910-K913), Zollinger-Ellison syndrome (E164), systemic sclerosis (M34), achalasia (K220), pyloric obstruction (K311-K315), obesity (E66.x), alcoholic liver disease (K70.x), or ascites (K7151, R18, C786, A1830) because these diseases increase the risk for GERD.

Among subjects in the present study, 39,987 patients with COPD used medical services more than once per year for GERD (K21, K210, K219), and 101,070 patients with COPD did not have GERD.

\section{Measures}

\section{Baseline characteristics}

The variables considered to be baseline characteristics were sex, age, insurance type, hospitalization and ICU hospitalization, number of ER visits, presence of chest Xrays, spirometry, chest CT, esophagogastroduodenoscopy, 24-h esophageal $\mathrm{pH}$ monitoring and esophagography, COPD severity, and comorbidity. The 'severe' COPD group comprised patients who visited a tertiary medical institution and were prescribed ICS + LABA + LAMA, ICS + LABA + oral corticosteroid (OCS), or LAMA + OCS more than once per year, and the 'not severe' group comprised the remaining study subjects. ER visits were defined as cases in which an outpatient or hospitalization claim was made for emergency medical service fees or in which additional holiday/night service fees were incurred. Comorbidities included ischemic heart disease (I20.x-I25.x, except I20.1), osteoporosis (M80.x-M82.x), depressive disorder (F32.x-F33.x), arthritis (M05.x-M09.x, M13.x), diabetes mellitus (E10.x-E14.x), congestive heart failure (I50, I50.0, I50.1, I50.9), hypertension (I10.x), anemia (D50.xD53.x, D63.x), metabolic syndrome (E66, E78.0, E78.4, E78.5), Barrett's esophagus (B227), gastric ulcer (K25.x), duodenal ulcer (K26.x), peptic ulcer (K27.x-K28.x), and gastroduodenitis (K29.x). 


\section{Medications used}

Medications considered in the present study included ICSs, ICSs/LABAs, LAMAs, LABAs, leukotriene receptor antagonists (LTRAs), OCSs, SAMAs, SABAs, SABAs/SAMAs, oral beta- 2 agonists, and theophylline covering all form of drug such as oral medications, injections, and inhalations.

\section{Exacerbation of COPD}

Exacerbation was defined as hospitalization or ER visits. Only subjects who were admitted to the department of internal medicine and received systemic corticosteroids during at least three days or recorded as ICD code for COPD exacerbation were included. Cases receiving systemic corticosteroids and inhaled short-acting bronchodilators at ER visits were included.

\section{Statistical analyses}

Data were analyzed using the SAS statistical program (ver. 9.2 [SAS Institute]); details of the analytical methods were as follows.

First, frequencies and percentages were calculated to enable comparison of baseline characteristics between COPD patients with GERD and those without GERD; the chi-squared test was used for categorical data, and the $t$-test was used for continuous data.

Second, the difference in medication usage between groups was determined using frequencies and percentages.

Third, univariate logistic regression was performed to understand the relationship between the general characteristics of patients with COPD and the presence of GERD, and multiple logistic regression was performed, with general characteristic variables included in the model.

Fourth, univariate logistic regression was performed to understand the relationship between the co-morbidity of patients with COPD and the presence of GERD, and the relationship between the medication usage of patients with COPD and the presence of GERD. Additionally, multiple logistic regression analysis was performed with adjustment for sex, age, type of health insurance, history of hospitalization and ICU hospitalization, category of ER visit, and COPD severity.

Fifth, univariate logistic regression was performed to understand the relationship between the presence of GERD in patients with COPD and the exacerbation of COPD, and multiple logistic regression was performed with adjustment for sex, age, type of health insurance, and COPD severity.

\section{Results}

The prevalence of GERD in patients with COPD was $28 \%(39,987 / 141,057)$.
General characteristics of patients with COPD according to the presence or absence of GERD were summarized in Table 1. COPD patients with GERD had more hospitalization and ER visits than those without GERD (all $p<0.001$ ), whereas there was no difference of ICU hospitalization between two groups. More patients with COPD and GERD used medical services for treatment of all kinds of comorbidity than did those without GERD (all $p<0.001$; Table 1 ).

Medication used for both group was summarized in Table 2 .

A regression model including general characteristics indicated that more female than male patients with COPD had GERD and more patients in their 50s, 60s, and 70s had GERD compared with those in their 40s. More GERD was observed in the medical aid group compared with the health insurance group, and in subjects with hospitalization experience compared with subjects without hospitalization. Less GERD was observed in subjects with ICU hospitalization than in those without. More GERD were observed in subjects with ER visits compared with those without (Table 3).

After adjusting for sex, age, type of health insurance, hospitalization, ICU hospitalization, category of ER visit, and COPD severity, more patients with COPD and GERD had comorbidities except congestive heart failure. More GERD was observed among patients using ICSs, ICSs/LABAs, LTRAs, OCSs, oral beta- 2 agonists, and theophylline (all $p<0.001$ ). However, less GERD was observed in association with SAMAs use [odds ratio (OR) 0.96, 95\% confidence interval (CI) 0.93 to 0.99; Table 4].

After adjusting for sex, age, type of health insurance, and COPD severity, the regression model demonstrated that COPD exacerbation was more prevalent among patients with GERD than among those without GERD, as indicated by more hospitalization (OR 1.54, 95\% CI 1.50 to 1.58 ) and ER visits (OR 1.55, 95\% CI 1.48 to 1.62 ; Table 5).

\section{Discussion}

To the best of our knowledge, this is the first nationwide study of the largest number of COPD patients to investigate the prevalence of GERD and the association between COPD and GERD. The prevalence of GERD in patients with COPD was $28 \%$, which is very high since the prevalence in Korean general population is around $12 \%$. It is similar to previous ones reported in Japan $[7,24]$, and lower than the others, which were $32 \%-37 \%$ in the USA and $53.6 \%$ in Iran [6,20,23], even though these studies investigated only a small number of patients with COPD. Some of them showed higher prevalence in COPD patients compared with controls $[7,20]$. These support that GERD is one of the most common comorbidities in patients with COPD. 
Table 1 General characteristic of subjects with COPD, classified according to the presence of GERD

\begin{tabular}{|c|c|c|c|c|c|c|}
\hline & \multirow{2}{*}{ Variables } & \multicolumn{2}{|c|}{ COPD with GERD } & \multicolumn{2}{|c|}{ COPD without GERD } & \multirow[b]{2}{*}{$p$} \\
\hline & & No. & (\%) & No. & (\%) & \\
\hline Total & & 39,987 & $(100.0)$ & 101,070 & $(100.0)$ & \\
\hline \multirow[t]{3}{*}{ Sex } & & & & & & $<0.001$ \\
\hline & Male & 22,967 & $(57.4)$ & 61,674 & $(61.0)$ & \\
\hline & Female & 17,020 & $(42.6)$ & 39,396 & (39.0) & \\
\hline
\end{tabular}

Age (years)

Mean \pm SD
$40-49$
$50-59$
$60-69$
$70-79$
$80+$

Type of insurance

$$
\begin{aligned}
& \text { Health insurance } \\
& \text { Medical aid }
\end{aligned}
$$

Hospitalization

$$
\begin{aligned}
& \text { Never } \\
& \text { Ever }
\end{aligned}
$$

ICU hospitalization

Never
Ever

No. of ER visits

$$
\begin{aligned}
& \text { Mean } \pm S D \\
& 0 \\
& 1-2 \\
& 3-4 \\
& 5+
\end{aligned}
$$

Chest X-ray

$$
\begin{aligned}
& \text { Never } \\
& \text { Ever }
\end{aligned}
$$

Spirometry

$$
\begin{aligned}
& \text { Never } \\
& \text { Ever }
\end{aligned}
$$

Chest CT

$$
\begin{aligned}
& \text { Never } \\
& \text { Ever }
\end{aligned}
$$

Esophagogastroduodenoscopy

$$
\begin{aligned}
& \text { Never } \\
& \text { Ever }
\end{aligned}
$$

24-h esophageal pH monitoring

$$
\begin{aligned}
& \text { Never } \\
& \text { Ever }
\end{aligned}
$$

Esophagography

\begin{tabular}{ll}
\multicolumn{2}{c}{$68.86 \pm 10.18$} \\
1,904 & $(4.8)$ \\
5,349 & $(13.4)$ \\
11,954 & $(29.9)$ \\
15,239 & $(38.1)$ \\
5,541 & $(13.9)$
\end{tabular}

32,823

7,164

24,179

15,808

39,817

170

$\begin{array}{cc} & 1.65 \pm 1.24 \\ 31,260 & (78.2) \\ 7,446 & (18.6) \\ 984 & (2.5) \\ 297 & (0.7)\end{array}$

(82.1)

(17.9)

(60.5)

(99.6)

(0.4)

5,243
13,052
26,801
37,329
18,645

$69.71 \pm 11.67$

(18.4)

85,755

15,315

70,547

30,523

100,605

465

$<0.001$

(84.8)

(15.2)

$<0.001$

(69.8)

(30.2)

0.377

(99.5)

(0.5)

$\begin{array}{ccc} & 1.50 \pm 1.02 & \\ 84,116 & (83.2) \\ 15,121 & (15.0) \\ 1,506 & (1.5) \\ 327 & (0.3)\end{array}$

22,671

(56.7)

(43.3)

65,494

35,576

(58.4)

(41.6)

23,353

16,634

(99.0)

(1.0)

39,583

404

27,923

12,064

(69.8)

(30.2)

39,974

13

(100.0)

(0.0)

39,352

(98.4)

65,891

35,179

100,159

911

94,638

6,432

101,067

3
0.055

$<0.001$

$<0.001$

$<0.001$

$<0.001$

$<0.001$

$<0.001$

$<0.001$

(65.2)

(34.8)

(99.1)

(0.9)

(93.6)

(6.4)

(100.0)

(0.0)

(99.5) 
Table 1 General characteristic of subjects with COPD, classified according to the presence of GERD (Continued)

\begin{tabular}{|c|c|c|c|c|c|c|}
\hline & Ever & 635 & $(1.6)$ & 504 & $(0.5)$ & \\
\hline COPD severity & & & & & & $<0.001$ \\
\hline & No & 32,629 & (81.6) & 84,427 & (83.5) & \\
\hline & Yes & 7,358 & $(18.4)$ & 16,643 & $(16.5)$ & \\
\hline \multicolumn{7}{|l|}{ Comorbidity } \\
\hline & Ischemic heart disease & 8,262 & (20.7) & 15,696 & $(15.5)$ & $<0.001$ \\
\hline & Osteoporosis & 8,723 & $(21.8)$ & 15,281 & $(15.1)$ & $<0.001$ \\
\hline & Depressive disorder & 4,838 & $(12.1)$ & 6,442 & $(6.4)$ & $<0.001$ \\
\hline & Arthritis & 10,299 & $(25.8)$ & 18,035 & $(17.8)$ & $<0.001$ \\
\hline & Diabetes mellitus & 10,426 & $(26.1)$ & 22,478 & $(22.2)$ & $<0.001$ \\
\hline & Congestive heart failure & 3,819 & $(9.6)$ & 8,661 & (8.6) & $<0.001$ \\
\hline & Hypertension & 20,734 & $(51.9)$ & 48,802 & $(48.3)$ & $<0.001$ \\
\hline & Anemia & 2,354 & $(5.9)$ & 3,973 & $(3.9)$ & $<0.001$ \\
\hline & Metabolic syndrome & 9,296 & $(23.2)$ & 16,428 & $(16.3)$ & $<0.001$ \\
\hline & Barrett's esophagus & 23 & $(0.1)$ & 4 & $(0.0)$ & $<0.001$ \\
\hline & Gastric ulcer & 14,308 & (35.8) & 17,940 & (17.8) & $<0.001$ \\
\hline & Duodenal ulcer & 2,489 & $(6.2)$ & 2,404 & $(2.4)$ & $<0.001$ \\
\hline & Peptic ulcer & 8,856 & (22.1) & 13,657 & $(13.5)$ & $<0.001$ \\
\hline & Gastroduodenitis & 36,196 & $(90.5)$ & 77,151 & (76.3) & $<0.001$ \\
\hline
\end{tabular}

No. = number of subjects; $S D=$ standard deviation; $I C U=$ intensive care unit; $E R=$ emergency room.

In the present study, several things are different from the previous studies. One is that inhaled anticholingergics may decrease or, at least, not increase risk of GERD, whereas a previous study reported that relative risk of GERD increased with using inhaled anticholinergics [22]. In another study, the effect of medication was not statistically significant or hard to be evaluated because COPD patients are usually treated by multiple medications and have both pulmonary and other systemic problems [21]. Our hypothesis is that inhaled anticholinergics might reduce GER through suppressing cough. They have been used for chronic cough [25], which is one of the most common symptoms in COPD patients. Chronic bronchitis and GERD are the most common causes of chronic cough [26]. Ipratropium has been effective even for cough hypersensitivity induced by upper respiratory tract infection [27]. Tiotropium inhibits cough reflex sensitivity to capsaicin in subjects with acute viral upper respiratory tract infection [28]. The antitussive effect of tiotropium may occur

Table 2 Medication utilization of patients with COPD, classified according to the presence of GERD

\begin{tabular}{lcccc}
\hline & \multicolumn{2}{c}{ COPD with GERD $(\boldsymbol{n}=\mathbf{3 9 , 9 8 7 )}$} & \multicolumn{2}{c}{ COPD without GERD $(\boldsymbol{n}=\mathbf{1 0 1 , 0 7 0 )}$} \\
\cline { 2 - 4 } \cline { 3 - 5 } ICS & No. & $(\%)$ & No. & $(\%)$ \\
ICS/LABA & 6,439 & $(8.8)$ & 12,734 & $(7.7)$ \\
LAMA & 14,436 & $(19.6)$ & 33,593 & $(20.3)$ \\
LABA & 11,760 & $(16.0)$ & 28,529 & $(17.2)$ \\
LTRA & 35 & $(0.0)$ & 23,158 & $(0.0)$ \\
OCS & 11,468 & $(15.6)$ & 51,421 & $(14.0)$ \\
SAMA & 24,031 & $(32.7)$ & 16,850 & $(10.2)$ \\
SABA & 7,763 & $(10.6)$ & 32,904 & $(19.9)$ \\
SABA/SAMA & 14,596 & $(19.9)$ & 2,603 & $(1.6)$ \\
Oral beta-2 agonists & 1,048 & $(1.4)$ & 55,856 & $(33.7)$ \\
Theophylline & 23,530 & $(32.0)$ & 83,688 & $(50.5)$ \\
\hline
\end{tabular}

No. = number of subjects; ICS = inhaled corticosteroid; $L A B A=$ long-acting beta-2 agonist; $L A M A$ = long-acting muscarinic antagonist; $L T R A=$ leukotriene receptor antagonist; $O C S=$ oral corticosteroid; $S A M A=$ short-acting muscarinic antagonist; $S A B A=$ short-acting beta-2 agonist. 
Table 3 Association of GERD with general characteristics in patients with COPD

\begin{tabular}{|c|c|c|c|c|c|c|}
\hline & \multicolumn{3}{|c|}{ Unadjusted } & \multicolumn{3}{|c|}{ Adjusted* } \\
\hline & OR & $95 \% \mathrm{Cl}$ & $p$ & OR & $95 \% \mathrm{Cl}$ & $p$ \\
\hline \multicolumn{7}{|l|}{ Sex } \\
\hline Male & 1 (ref) & & & 1 (ref) & & \\
\hline Female & 1.16 & $(1.13,1.19)$ & $<0.001$ & 1.22 & $(1.19,1.25)$ & $<0.001$ \\
\hline \multicolumn{7}{|l|}{ Age (years) } \\
\hline $40-49$ & 1 (ref) & & & 1 (ref) & & \\
\hline $50-59$ & 1.13 & $(1.06,1.20)$ & $<0.001$ & 1.15 & $(1.08,1.22)$ & $<0.001$ \\
\hline $60-69$ & 1.23 & $(1.16,1.30)$ & $<0.001$ & 1.26 & $(1.19,1.34)$ & $<0.001$ \\
\hline $70-79$ & 1.12 & $(1.06,1.19)$ & $<0.001$ & 1.10 & $(1.04,1.17)$ & $<0.001$ \\
\hline $80+$ & 0.82 & $(0.77,0.87)$ & $<0.001$ & 0.75 & $(0.71,0.80)$ & $<0.001$ \\
\hline \multicolumn{7}{|l|}{ Type of insurance } \\
\hline Health insurance & 1 (ref) & & & 1 (ref) & & \\
\hline Medical aid & 1.22 & $(1.19,1.26)$ & $<0.001$ & 1.15 & $(1.12,1.19)$ & $<0.001$ \\
\hline \multicolumn{7}{|l|}{ Hospitalization } \\
\hline Never & 1 (ref) & & & 1 (ref) & & \\
\hline Ever & 1.51 & $(1.48,1.55)$ & $<0.001$ & 1.46 & $(1.42,1.50)$ & $<0.001$ \\
\hline \multicolumn{7}{|l|}{ ICU hospitalization } \\
\hline Never & 1 (ref) & & & 1 (ref) & & \\
\hline Ever & 0.93 & $(0.78,1.10)$ & 0.385 & 0.68 & $(0.57,0.82)$ & $<0.001$ \\
\hline \multicolumn{7}{|l|}{ Number of ER visits } \\
\hline 0 & 1 (ref) & & & 1 (ref) & & \\
\hline $1-2$ & 1.33 & $(1.29,1.37)$ & $<0.001$ & 1.11 & $(1.07,1.15)$ & $<0.001$ \\
\hline $3-4$ & 1.76 & $(1.62,1.91)$ & $<0.001$ & 1.40 & $(1.29,1.53)$ & $<0.001$ \\
\hline $5+$ & 2.44 & $(2.09,2.86)$ & $<0.001$ & 1.87 & $(1.59,2.21)$ & $<0.001$ \\
\hline \multicolumn{7}{|l|}{ COPD severity } \\
\hline No & 1 (ref) & & & 1 (ref) & & \\
\hline Yes $^{\dagger}$ & 1.14 & $(1.11,1.18)$ & $<0.001$ & 1.02 & $(0.99,1.06)$ & 0.186 \\
\hline
\end{tabular}

$O R=$ odds ratio; $I C U=$ intensive care unit; $E R=$ emergency room.

*Adjusted for sex, age, type of insurance, hospitalization, ICU hospitalization, number of ER visits by category, and COPD severity.

'The 'severe' group comprised patients who visited a tertiary medical institution and were prescribed ICS + LABA + LAMA, ICS + LABA + oral corticosteroid (OCS), or LAMA + OCS more than once per year.

through a mechanism other than bronchodilation. Additionally, tiotropium reduced lung inflammation in a mouse model of chronic GER [29]. Even though ICSs have been known to be effective for chronic cough, especially asthma [26], our subjects exclusively had COPD. The prevalence of GER was reported to increase according to use of ICS in COPD patients [22], which is consistent with our result. Combined inhalers of ICS and LABA have been popular in Korea, whereas use of LABA alone was very limited because representative LABAs such as salmeterol or formoterol were no longer imported or produced. The reason was that salmeterol as a single agent without ICS seemed to increase respiratory mortality in patients with asthma [30], which made physicians hesitate to prescribe LABA without ICS even for COPD. Therefore it is inadequate to evaluate their effects on GERD. When a patient takes variable drugs at the same time, as well as COPD medication, drug interaction will happen.

Another different thing is that ICU admission due to COPD exacerbation was not associated with GERD. It may be possible for COPD patients with GERD to complain more cough or heartburn and feel exacerbation earlier than do those without GERD, which make them more frequently have unscheduled visit or ER visit, leading to hospitalization to general ward but not to ICU. The other possibility is that patients with COPD to be admitted to ICU do not have chance to be examined whether they have GERD or they are too dyspneic to present any symptoms of GERD. Despite of higher proportion of comorbidities in patients with COPD and GERD, the rate of ICU admission was lower than those 
Table 4 Association of GERD with comorbidities and medication utilization in patients with COPD

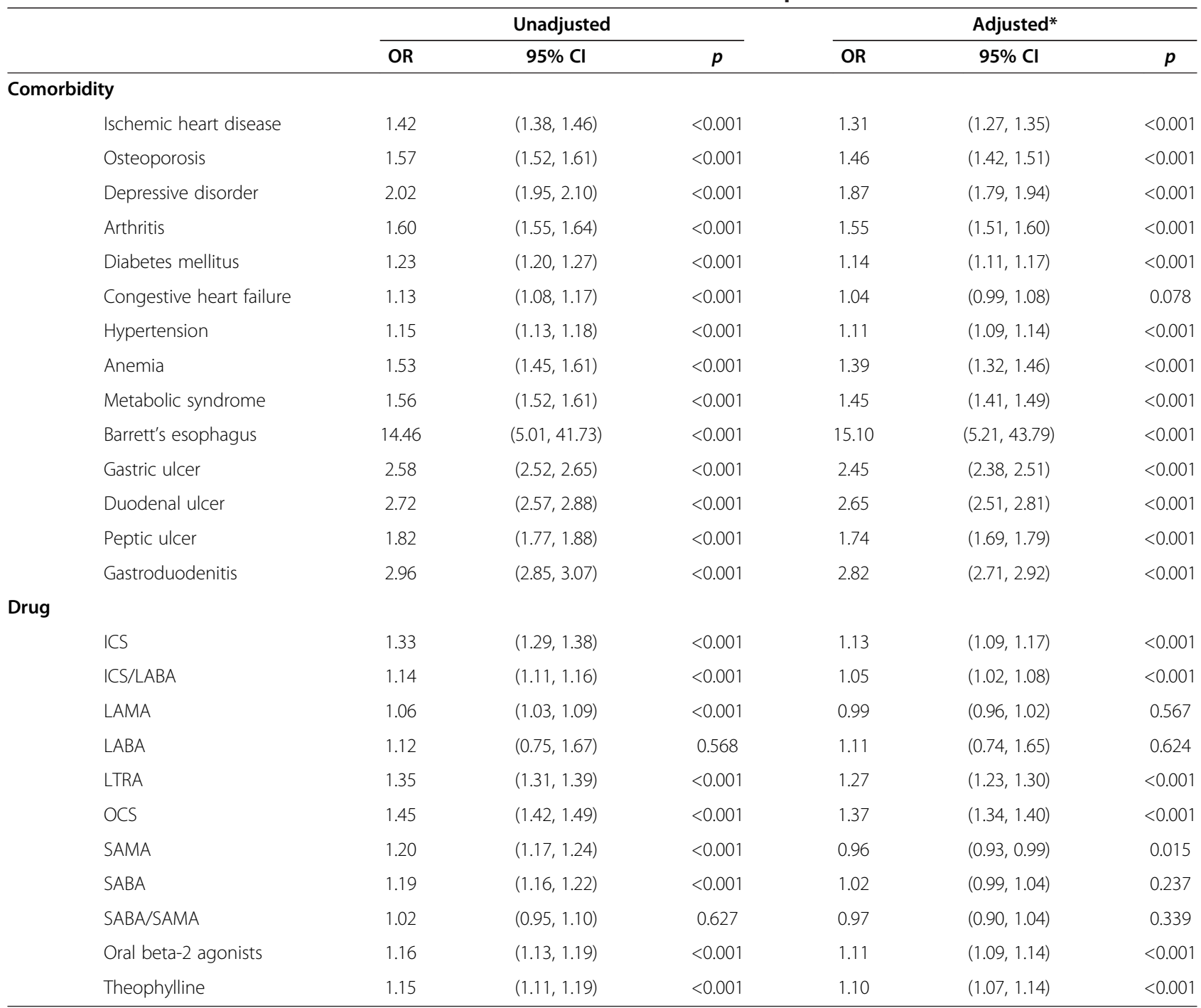

$O R=$ odds ratio; $I C S$ = inhaled corticosteroid; $L A B A=$ long-acting beta-2 agonist; $L A M A=$ long-acting muscarinic antagonist; $L T R A=$ leukotriene receptor antagonist; $O C S=$ oral corticosteroid; $S A M A=$ short-acting muscarinic antagonist; $S A B A=$ short-acting beta-2 agonist.

"Adjusted for sex, age, type of health insurance, hospitalization, ICU hospitalization, number of ER visits by category, and COPD severity.

in those without GERD, even though total hospitalization rate was higher. There would be the third possibility. In this study, prescriptions of proton pump inhibitors (PPIs) were given for COPD patients with GERD more frequently than those without GERD (data are not shown). PPIs decrease frequency of GERD symptoms such as cough [31], which would rather prevent COPD patients from progression to ICU admission. One small prospective study demonstrated that PPIs reduced the number of exacerbation in COPD patients without GERD [32].

Table 5 Association of GERD with exacerbation in patients with COPD

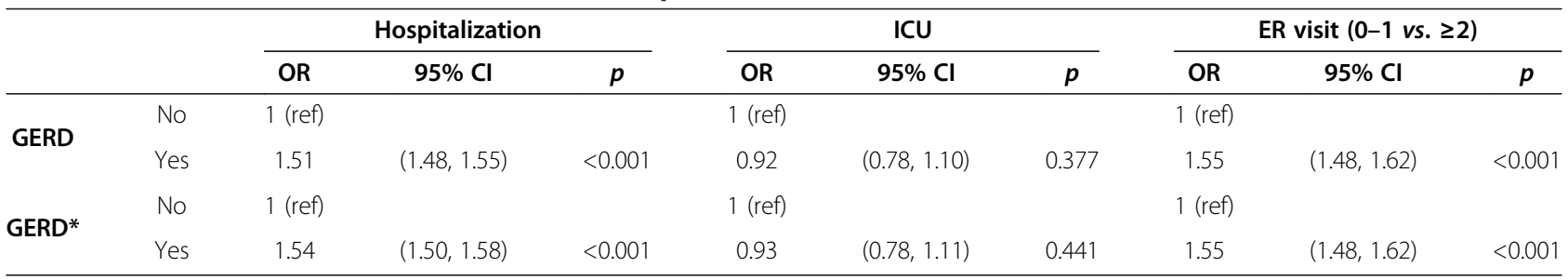

$I C U=$ intensive care unit; $E R=$ emergency room; $O R=$ odds ratio.

${ }^{*}$ Adjusted for sex, age, type of health insurance, and COPD severity. 
In this study, the logistic regression analysis, even after adjusting several factors such as age, gender, type of health insurance, and COPD severity, showed that the presence of GERD was independently associated with COPD exacerbation such as hospitalization or frequent ER visits. Since lung function data were not available in the present study, definition of severe COPD was based upon medication information and health care resource utilization. Although the degree of airflow limitation has been used as one of the most important criteria of COPD severity, it does not always reflect dyspnea, exercise capacity, quality of life, or exacerbation frequency [33]. Recently updated Global initiative for chronic Obstructive Lung Disease (GOLD) emphasizes combined assessment of COPD, which includes symptoms and risk of exacerbations as well as degree of airflow limitation [3]. To supplement our weakness, patients with severe COPD were defined as those who satisfied both of the followings. One is that they used a tertiary health care resource, which means respiratory specialist's care, and the other is that they received medications for maximum effect such as triple therapy (ICS + LABA + LAMA) or OCS-containing long-acting bronchodilator, which may mean medication for exacerbations. These are possible under nationwide health insurance system of Korea, which divide health care resources into primary, secondary and tertiary and recommend people to use those step by step. Previous studies observed very small number of patients and simply compared frequency of exacerbation in COPD patients with GERD with in those without GERD $[6,7,23,24]$. They did not fully consider clinically important confounding factors such as age, gender, and COPD severity. Moreover, in two reports of them, COPD patients with GERD showed lower lung function as well as higher frequency of exacerbation than did those without GERD [23,24]. Therefore it might be hard to conclude whether frequent exacerbation was related to the presence of GERD or severe airflow limitation. Our study is also limited by its retrospective and crosssectional design, and thus we cannot definitely conclude that GERD causes exacerbations of COPD. However, in a recent prospective study, patients with COPD and GERD had more exacerbation and hospitalization than in those without GERD, with crude relative risks of 3.42 and 3.66, respectively [24]. Since they excluded patients taking drugs for acid suppression, their relative risks may be higher than odds ratio in this study reflecting real world.

There are several limitations of this study. GERD was defined only by diagnosis codes even though about one third of GERD patients performed diagnostic tests related to GERD. In Korea, diseases of upper gastrointestinal (UGI) tract are more common than those in western countries and the incidence of stomach cancer has been the highest among all types of cancer. Therefore, as a health screening program of the Korean National Health Insurance System, all people can receive one of EGD or UGI series every two years from the age of 40 years. Nevertheless there might be a selection bias since symptomatic patients are likely to receive a diagnostic test. Definition of COPD was based on both of diagnosis codes and prescription data, which were exclusively determined by physicians. Although $37 \%$ of our subjects performed spirometry, this figure includes both general physicians and specialists. To exclude asthma patients, we excluded those receiving only LTRA or only ICS or only SABA. Nevertheless, there was still a possibility that some of our subjects may have asthma. As considering this, we additionally analyzed each data from only male or from subjects with prescription including LAMA, which is specific for COPD (Additional file 1: Table S1 and Table S2). Both analyses showed the same trend as Table 5. Since we used health insurance claim data, relatively important clinical data such as smoking history, lung function, and body mass index cannot be quantified although we tried to exclude patients with asthma or those with obesity or other diseases increasing risk of GERD by using both diagnosis codes and prescription data. Relatively not severe exacerbation such as unscheduled clinic visits or medication change were not included. Also, our definition of exacerbation might exclude some patients receiving only antibiotics without systemic corticosteroid. However, despite of these limitations, the present study clearly exhibits various interactive relationships between COPD and GERD. Although it would be hard to conclude complex relationship between COPD and GERD considering own severity and specific medications for both diseases and their interactions, we need to pay more attention to unraveling the heterogeneous causes of exacerbations.

\section{Conclusions}

GERD is one of the most common comorbidities and a factor associated with exacerbation in patients with COPD. COPD-related medications except inhaled anticholinergics are associated with increased risk of GERD.

\section{Additional files}

Additional file 1: Table S1. Association of GERD with exacerbation in male patients with COPD. Table S2 Association of GERD with exacerbation in patients with COPD receiving LAMAs.

\section{Abbreviations}

COPD: Chronic obstructive pulmonary disease; GERD: Gastroesophageal reflux disease; HIRA: Korean Health Insurance Review and Assessment Service; ICU: Intensive care unit; ER: Emergency room; ICS: Inhaled corticosteroid; LABAs: Long-acting beta-2 agonists; LAMAs: Long-acting muscarinic antagonists; SAMAs: Short-acting muscarinic antagonists; SABAs: Short-acting beta-2 agonists; OCS: Oral corticosteroid; 
LTRAs: Leukotriene receptor antagonists; OR: Odds ratio; Cl: Confidence interval; PPIs: Proton pump inhibitors.

\section{Competing interests}

YMO has been an investigator in university-sponsored studies (Asan Institute for Life Science, University of Ulsan College of Medicine) and an industrysponsored study (MSD Korea and AstraZeneca Korea) and has participated as a speaker at scientific meetings organized and financed by various pharmaceutical companies (Handok, GlaxoSmithKline, AstraZeneca Korea, MSD Korea, and Boehringer Ingelheim) and a magazine company (Korea Doctors' Weekly). SDL serves as a consultant to GlaxoSmithKline and has participated as a speaker at scientific meetings organized and financed by various pharmaceutical companies (GlaxoSmithKline, AstraZeneca Korea, and Boehringer Ingelheim). The remaining authors have no conflicts of interest to disclose.

\section{Authors' contributions}

JK participated in data analysis and drafted the manuscript. JHL conceived the study, participated in the study design and drafted the manuscript. YK and KK participated in the study design and performed data analysis. YMO, KHY, CKR, HKY, YSK, YBP, SWL, and SDL participated in the study design and were involved in revising the manuscript. All authors read and approved the final manuscript.

\section{Acknowledgements}

This study was supported by a grant from the Korea Healthcare Technology R\&D Project (A102065)

\section{Author details}

${ }^{1}$ Office of Heath Service Research, National Evidence-Based Healthcare Collaborating Agency, Seoul, Korea. ${ }^{2}$ Department of Internal Medicine, School of Medicine, Ewha Womans University, Seoul, Korea. ${ }^{3}$ Department of Clinical Research Support, National Strategic Coordinating Center for Clinical Research, Seoul, Korea. ${ }^{4}$ Department of Pulmonary and Critical Care Medicine, Asan Medical Center, University of Ulsan College of Medicine, Seoul, Korea. ${ }^{5}$ Department of Internal Medicine, Konkuk University School of Medicine, Seoul, Korea. ${ }^{6}$ Department of Internal Medicine, Seoul St. Mary's Hospital, Catholic University of Korea, Seoul, Korea. ${ }^{7}$ Department of Internal Medicine, Yeouido St. Mary's Hospital, Catholic University of Korea, Seoul, Korea. ${ }^{8}$ Department of Internal Medicine, Yonsei University College of Medicine, Seoul, Korea. ${ }^{9}$ Department of Internal Medicine, Division of Pulmonary, Allergy, and Critical Care Medicine, Hallym University Kangdong Sacred Heart Hospital, Seoul, Korea.

Received: 19 December 2012 Accepted: 7 August 2013

Published: 9 August 2013

\section{References}

1. Donaldson GC, Seemungal TA, Bhowmik A, Wedzicha JA: Relationship between exacerbation frequency and lung function decline in chronic obstructive pulmonary disease. Thorax 2002, 57(10):847-852.

2. Soler-Cataluña JJ, Martínez-García MA, Román Sánchez P, Salcedo E, Navarro M, Ochando R: Severe acute exacerbations and mortality in patients with chronic obstructive pulmonary disease. Thorax 2005, 60(11):925-931.

3. Global Initiative for Chronic Obstructive Lung Disease (GOLD): Global strategy for diagnosis, management, and prevention of COPD. http://www. goldcopd.org/guidelines-global-strategy-for-diagnosis-management.html. Date last updated: February 2013. Date last accessed: July 122012.

4. Pratter MR: Overview of common causes of chronic cough: ACCP evidence-based clinical practice guidelines. Chest 2006, 129(Suppl):59-62.

5. Hurst JR, Vestbo J, Anzueto A, Locantore N, Müllerova H, Tal-Singer R, Miller B, Lomas DA, Agusti A, Macnee W, Calverley P, Rennard S, Wouters EF, Wedzicha JA, Evaluation of COPD Longitudinally to Identify Predictive Surrogate Endpoints (ECLIPSE) Investigators: Susceptibility to exacerbation in chronic obstructive pulmonary disease. N Engl J Med 2010, 363(12):1128-1138.

6. Rascon-Aguilar IE, Pamer M, Wludyka P, Cury J, Coultas D, Lambiase LR, Nahman NS, Vega KJ: Role of gastroesophageal reflux symptoms in exacerbations of COPD. Chest 2006, 130(4):1096-1101.

7. Terada K, Muro S, Sato S, Ohara T, Haruna A, Marumo S, Kinose D, Ogawa E, Hoshino Y, Niimi A, Terada T, Mishima M: Impact of gastro-oesophageal reflux disease symptoms on COPD exacerbation. Thorax 2008, 63(11):951-955.

8. Dent J, El-Serag HB, Wallander MA, Johansson S: Epidemiology of gastrooesophageal reflux disease: a systemic review. Gut 2005, 54(5):710-717.

9. Jung HK: Epidemiology of gastresophageal reflux disease in Asia: a systematic review. J Neurogastroenterol Motil 2011, 17(1):14-27.

10. Field SK, Evans JA, Price LM: The effects of acid perfusion of the esophagus on ventilation and respiratory sensation. Am J Respir Crit Care Med 1998, 157(4):1058-1062.

11. Cuttitta G, Cibella F, Visconti A, Scichilone N, Bellia V, Bonsignore G: Spontaneous gastresophageal reflux and airway patency during the night in adult asthmatics. Am J Respir Crit Care Med 2000, 161(1):177-181.

12. Alexander JA, Hunt LW, Patel AM: Prevalence, pathophysiology, and treatment of patients with asthma and gastresophageal reflux disease. Mayo Clin Proc 2000, 75(10):1055-1063.

13. Phua SY, McGarvey LP, Ngu MC, Ing AJ: Patients with gastro-oesophageal reflux disease and cough have impaired laryngopharyngeal mechanosensitivity. Thorax 2005, 60(6):488-491.

14. Sontag SJ, O'Connell S, Khandelwal S, Miller T, Nemchausky B, Schnell TG, Serlovsky R: Most asthmatics have gastroesophageal reflux with or without bronchodilator therapy. Gastroenterology 1990, 99(3):613-620.

15. Savarino E, Bazzica M, Zentilin P, Pohl D, Parodi A, Cittadini G, Negrini S, Indiveri F, Tutuian R, Savarino V, Ghio M: Gastroesophageal reflux and pulmonary fibrosis in scleroderma: a study using $\mathrm{pH}$-impedance monitoring. Am J Respir Crit Care Med 2009, 179(5):408-413.

16. Sweet MP, Patti MG, Hoopes C, Hays SR, Golden JA: Gastro-oesophageal reflux and aspiration in patients with advanced lung disease. Thorax 2009, 64(2):167-173.

17. Pauwels A, Blondeau K, Dupont $\sqcup$, Sifrim D: Mechanisms of increased gastroesophageal reflux in patients with cystic fibrosis. Am J Gastroenterol 2012, 107(9):1346-1353.

18. Stein MR, Towner TG, Weber RW, Mansfield LE, Jacobson KW, McDonnell JT, Nelson HS: The effect of theophylline on the lower esophageal sphincter pressure. Ann Allergy 1980, 45(4):238-241.

19. Crowell MD, Zayat EN, Lacy BE, Schettler-Duncan A, Liu MC: The effects of an inhaled beta(2)-adrenergic agonist on lower esophageal function: a dose-response study. Chest 2001, 120(4):1184-1189.

20. Mokhlesi B, Morris AL, Huang CF, Curcio AJ, Barrett TA, Kamp DW: Increased prevalence of gastresophageal reflux symptoms in patients with COPD. Chest 2001, 119(4):1043-1048.

21. Casanova C, Baudet JS, del Valle VM, Martin JM, Aguirre-Jaime A, de Torres $J P$, Celli BR: Increased gastro-oesophageal reflux disease in patients with severe COPD. Eur Respir J 2004, 23(6):841-845.

22. García Rodríguez LA, Ruigómez A, Martín-Merino E, Johansson S, Wallander MA: Relationship between gastresophageal reflux disease and COPD in UK primary care. Chest 2008, 134(6):1223-1230.

23. Rogha M, Behravesh B, Pourmoghaddas Z: Association of gastresophageal reflux disease symptoms with exacerbations of chronic obstructive pulmonary disease. J Gastrointestin Liver Dis 2010, 19(3):253-256.

24. Takada K, Matsumoto S, Kojima E, Iwata S, Okachi S, Ninomiya K, Morioka H, Tanaka K, Enomoto Y: Prospective evaluation of the relationship between acute exacerbations of COPD and gastroesophageal reflux disease diagnosed by questionnaire. Respir Med 2011, 105(10):1531-1536.

25. Braman SS: Chronic cough due to chronic bronchitis: ACCP evidencebased clinical practice guidelines. Chest 2006, 129(1 Suppl):104-115.

26. Molassiotis A, Bryan G, Caress A, Bailey C, Smith J: Pharmacological and non-pharmacological interventions for cough in adults with respiratory and non-respiratory diseases: a systematic review of the literature. Respir Med 2010, 104(7):934-944.

27. Lowry R, Wood A, Higenbottam T: The effect of anticholinergic bronchodilator therapy on cough during upper respiratory tract infections. Br J Clin Pharmacol 1994, 37(2):187-191.

28. Dicpinigaitis PV, Spinner L, Santhyadka G, Negassa A: Effect of tiotropium on cough reflex sensitivity in acute viral cough. Lung 2008, 186(6):369-374.

29. Cui Y, Devillier P, Kuang X, Wang H, Zhu L, Xu Z, Xia Z, Zemoura L, Advenier $\mathrm{C}$, Chen $\mathrm{H}$ : Tiotropium reduction of lung inflammation in a model of chronic gastro-oesophageal reflux. Eur Respir J 2010, 35(6):1370-1376.

30. Nelson HS, Weiss ST, Bleecker ER, Yancey SW, Dorinsky PM, SMART Study Group: The Salmeterol Multicenter Asthma Research Trial: a comparison of usual pharmacotherapy for asthma or usual pharmacotherapy plus salmeterol. Chest 2006, 129(1):15-26. 
31. Poe RH, Kallay MC: Chronic cough and gastresophageal reflux disease: experience with specific therapy for diagnosis and treatment. Chest 2003, 123(3):679-684.

32. Sasaki T, Nakayama K, Yasuda H, Yoshida M, Asamura T, Ohrui T, Arai H,

Araya J, Kuwano K, Yamaya M: A randomized, single-blind study of lansoprazole for the prevention of exacerbations of chronic obstructive pulmonary disease in older patients. J Am Geriatr Soc 2009, 57(8):1453-1457.

33. Agusti A, Calverley PM, Celli B, Coxson HO, Edwards LD, Lomas DA, MacNee W, Miller BE, Rennard S, Silverman EK, Tal-Singer R, Wouters E, Yates JC, Vestbo J, Evaluation of COPD Longitudinally to Identify Predictive Surrogate Endpoints (ECLIPSE) investigators: Characterisation of COPD heterogeneity in the ECLIPSE cohort. Respir Res 2010, 11:122.

doi:10.1186/1471-2466-13-51

Cite this article as: Kim et al:: Association between chronic obstructive pulmonary disease and gastroesophageal reflux disease: a national cross-sectional cohort study. BMC Pulmonary Medicine 2013 13:51.

\section{Submit your next manuscript to BioMed Central and take full advantage of:}

- Convenient online submission

- Thorough peer review

- No space constraints or color figure charges

- Immediate publication on acceptance

- Inclusion in PubMed, CAS, Scopus and Google Scholar

- Research which is freely available for redistribution 